\title{
"Como este corpo se dançando em si" ou o trabalho da forma segundo Jorge de Sena
}

\author{
Mônica Genelhu Fagundes \\ (Universidade Federal do Rio de Janeiro)
}

\section{RESUMO}

Um poema lê uma fotografia que fixa um passo de dança: assim Jorge de Sena compõe "O dançarino de Brunei", de Metamorfoses. Retomando este entrelaçamento de linguagens - poesia, fotografia, dança - proposto pelo poeta, pretendemos, a partir da análise do poema e da fotografia com a qual dialoga diretamente, e explorando os núcleos de sentido que nesta relação se destacam (corpo, gesto, imagem, tempo, história), pensar o que seria o trabalho da forma - a metamorfose - segundo Jorge de Sena, buscando apreender sua motivação dialeticamente articulada de intervenção estética e investimento ético sobre o real.

PALAVRAS-CHAVE: Jorge de Sena, metamorfose, diálogo interartes

\section{ABSTRACT}

A poem reads a photograph which seizes a dance step: thus Jorge de Sena composes "The dancer of Brunei", in Metamorphoses. Examining this intermingling of languages - poetry, photography, dance - proposed by the poet, we aim, starting with the analysis of the poem itself and the photograph to which it relates, and furthermore exploring the core meanings standing out in this relationship (body, gesture, image, time, history) to think about what would be the work of form - the metamorphosis - according to Jorge de Sena, hoping to understand his dialectically articulated motivation, which combines aesthetic intervention and ethical investment on reality.

KEYWORDS: Jorge de Sena, metamorphosis, inter-arts dialogue 


\section{Dançarino de Brunei}

\section{Ao Ruy Cinatti}

Em fortes linhas de contorno suave e em passos que se pousam prolongando o gesto da nudez quase completa (ou sim, completa, pois que um breve pano descendo da cintura nada cobre ou veste) de um corpo que se ondula duro e frágil como de amor a força requebrada, a mesma dança nesta imagem quieta é suspendida num momento. Os pés assentam, um, nos dedos só, e o outro cruzado à frente a perna torce um pouco. Maçãs do rosto e os olhos concentrados são como a franja do cabelo fluidos neste relevo brônzeo de uma luz de lado. E ao torço que da cinta se levanta um colar marca as linhas do pescoço em que a cabeça se ergue delicada. É de Bornéu e um povo primitivo esta figura. Uma elegância tal são séculos de humana perfeição que gente gera num saber da vida. Quando será que de ocidente a morte virá matar-nos, antes que matemos com deuses feitos homens os humanos deuses que já tão poucos sobrevivem límpidos como este corpo se dançando em si (e as mãos paradas segurando os ares)? (SENA, 1988, p. 131)

"Dançarino de Brunei" é o último poema inserido por Jorge de Sena em Metamorfoses (1963). Escrito em 1974, passou a fazer parte do livro na edição de 1978 de Poesia Il, acompanhado de uma nota do autor da qual citamos um fragmento:

Este poema foi inspirado pela fotografia que o ilustra e que era uma das que fazia parte do artigo, "Brunei, Abode of Peace» [residência de paz], de Joseph Judge, com fotos de Dean Conger, publicado em National Geographic, vol. 141, n. ${ }^{\circ}$ 2, Fevereiro de 1974. (...) 0 dançarino da foto, que não é já um jovem, pertence a uma das tribos - os Pumanas - mais fugidias do sultanato, nómadas que eram e eventualmente ainda são. (Sena, 1988, p. 221)

A nota de Sena realça algo que o próprio trabalho ecfrástico do poema deixa claro: o diálogo aqui proposto se dá com a fotografia que o acompanha. Diversamente do que encontramos nos demais pares obra 
plástica-poema de Metamorfoses, em que as fotografias que ilustram os textos parecem ser apenas um meio para indicar ou relembrar ao leitor de que objeto estes tratam, no caso de "Dançarino de Brunei" a materialidade da fotografia não é obliterada, sua superfície não se converte na transparência instrumental e irrelevante em si mesma que tão-somente dá a ver o objeto aí reproduzido. Se, em poemas como "Deméter", "'O Balouço', de Fragonard", e tantos outros do livro, Sena interpretava as obras reproduzidas nas fotografias; ou se em "'A cadeira amarela', de Van Gogh" fazia do quadro um meio de alcançar o próprio pintor; se em "Camões dirige-se aos seus contemporâneos" o busto do poeta utilizado como ilustração não terá talvez mais do que um paralelo de atitude com o formidável monólogo criado por Sena, em "Dançarino de Brunei", particularmente, a fotografia não apenas reproduz ou dá a ver um outro objeto - o dançarino; ela constitui a obra mesma sobre a qual o poema se detém: uma produção - não uma reprodução fotográfica, cujo estatuto se reconhece na indicação de autor - o fotógrafo Dean Conger - feita na legenda da foto e na nota de Sena. Isto que poderia parecer mínimo nuance de sentido faz deste poema um caso singular em Metamorfoses.

Para compreender as implicações e o sentido desta singularidade, caberá refletir sobre as particularidades da fotografia como operação sobre o real e pensar de que modo este trabalho fotográfico se torna relevante para a construção poética de Sena. Em primeiro lugar, será preciso verificar a própria definição do objeto do poema: não um dançarino, mas um dançarino fotografado; ou seja: não o índio pumana e o exercício de sua dança como elementos empíricos, dados objetivos do real, mas já esta realidade alterada, percebida e apreendida por um certo olhar que a transforma; referente real metamorfoseado em signo de representação, imbuído de sentido e valor. Trabalho fotográfico por excelência, como o define Rosalind Krauss, que atribui esta propriedade do ato fotográfico à sua operação fundamental: a imobilização do movimento. (KRAUSS, 2002, p. 120)

A interrupção do fluxo do tempo e sua concentração em um momento decisivo constituem a principal contribuição da fotografia moderna, identificada com o instantâneo. Como percebe Merleau-Ponty, "a fotografia mantém abertos os instantes que o avanço do tempo torna a fechar em seguida" (MERLEAU-PONTY, 2004, p. 42). Ela se revela, assim, embora obra plástica, trabalho que se cumpre sobre o tempo, que faz da duração sua matéria. Suspendendo o curso da passagem e da mutabilidade das coisas, a fotografia cristaliza formas na temporalidade nova do instante, que por meio dela se torna apreensível e analisável.

Este trabalho fotográfico de suspensão temporal e dilatação do instante, que, transformado em imagem, comporta experiência e saber, se revela emblematicamente - e talvez pudéssemos dizer mesmo alegoricamente - na imagem de Dean Conger que inspira o poema de Sena. Não se trata de qualquer instantâneo fotográfico, mas de uma fotografia de dança, arte que foi definida por Valéry, talvez seu mais devotado filósofo, como "uma forma de tempo, a criação de uma espécie de tempo" (VALÉRY, 1957, p. 1389). Na evolução de seus passos, a dançarina ideal de Valéry engendraria a duração com seu próprio corpo, gerando com seus movimentos o tempo particular em que se cumprem seus passos. Ela seria, assim, não uma mulher que dança, (para lembrar 
Mallarmé em sua não-definição da dançarina - MALLARMÉ, 2003, p. 201), mas "o ato puro das metamorfoses", como a caracteriza ainda Valéry (1996, p. 44): não um ser sólido, identificado, definido, mas o movimento e as transformações que produz, a metamorfose em ação. A dança seria, assim, encenação do tempo em sua mutabilidade. E fotografá-la seria, portanto, não apenas o ato de imobilizar o tempo - que é toda fotografia - mas, num movimento reflexivo, criar a imagem deste ato. Trabalho que não elimina a duração, que não cria um instante "fora do tempo", mas, de modo bem diverso, suspende a sua continuidade linear, criando um momento de concentração: instante ainda no tempo, passo de uma dança que não deixa de ser dança, mas que se suspende por um momento para que se possa saber e pensar seu gesto, sua significação.

É no instante dilatado produzido pela fotografia e na dobra de sentido que ela engendra que se inscreve o poema de Sena, leitura da imagem que desenvolve a reflexão por ela empreendida, trabalho gestual - imbuído, portanto, de sentido e valor - em que se tramam, como na dança, o corpo e o tempo. Como escreve Valéry, aqui "o instante gera a forma, e a forma faz ver o instante". Na "imagem quieta" em que a "dança (...) é suspendida num momento", Sena lê os sentidos de abertura - "o gesto da nudez quase completa" - e sedução - "como de amor a força requebrada" - que a fotografia propõe - como suspensão do tempo e apelo à reflexão que é - e a que o poema atende, percorrendo as "fortes linhas de contorno suave (...) de um corpo que se ondula duro e frágil". Este corpo cristalizado no tempo, ele próprio a concentrar em si o tempo como dança suspendida, se abre, assim, à metamorfose.

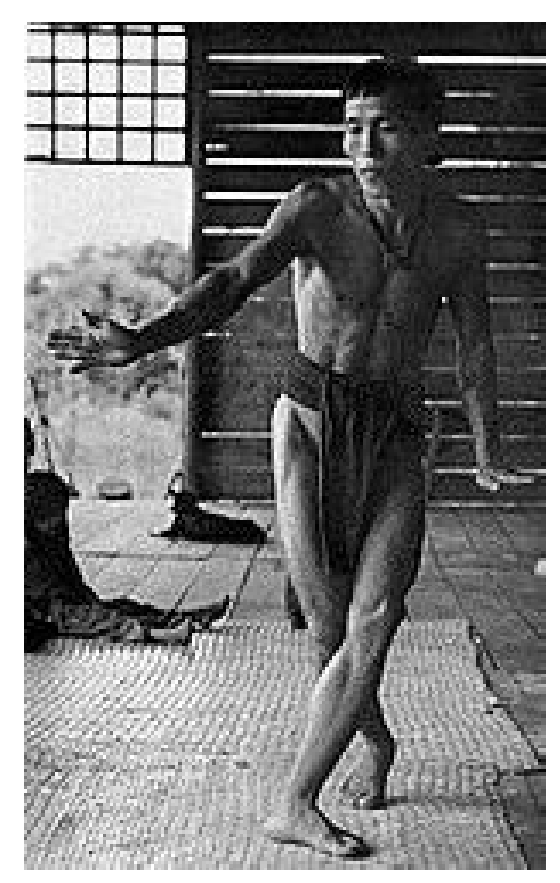

Primeiro plano da imagem de Dean Conger, no corpo do dançarino parecem se trançar as linhas que fora dele - no tapete que pisa, no assoalho de tábuas, nas ripas da parede e na grade ao fundo são rígidas retas paralelas e perpendiculares. Ele salta à frente do quadro, vértice primeiro do triângulo que forma com as pernas de um companheiro, a média distância, e o cachorro deitado mais atrás; jogo de composição cuja forma que se repete no corpo mesmo do dançarino, na posição de seus pés, no trançar de suas pernas, na abertura de seus braços, no 
desenho de seu rosto recortado pela luz. À frente, como se para ele confluísse e nele se ordenasse o que no seu cenário são apenas formas geométricas abstratas e fragmentos soltos, o dançarino se oferece como o lugar da unidade e do sentido, imagem de perfeição. Já não é um índio pumana que dança, mas imagem que a fotografia constrói como mais uma das obras de arte do "museu imaginário" que é o livro de Sena - "É de Bornéu e um povo primitivo / esta figura" - e que, como elas, se oferece à leitura, à apropriação e à transformação que o poema sobre ele irá operar, decompondo-o, alterando-o, estudando-o; primeiro como forma: "Maçãs do rosto e os olhos concentrados / são como a franja do cabelo fluidos / neste relevo brônzeo de uma luz de lado."; depois como signo "de humana perfeição / que gente gera num saber da vida".

Signo histórico: forma que incorpora o tempo - "são séculos de humana perfeição" -, que the dá corpo e que permanece suspensa, a concentrar sentidos diversos, aberta ao conhecimento e à reflexão, "como este corpo se dançando em si" na "imagem quieta" da fotografia. Instantâneo que imobiliza o movimento, que cristaliza o tempo, mas não o exclui. Como instante decisivo de uma dança suspendida - passo, estado, aspecto -, a fotografia guarda o traço da mutabilidade, é o vestígio possível da duração, tempo tornado signo e apreendido como rastro, concentrado como memória - e como virtualidade futura, já veremos num momento significativo. Tessitura complexa de tempo que encontra forma e se trama num corpo, como o do dançarino, no qual se ordenam e ganham vida e sentido as linhas abstratas do real que nele se dá a conhecer. Como explica Sena no "Post-fácio" a Metamorfoses. "acontece que o homem - se pode viver e criar abstrações - é pelo rosto e pelos seus gestos, e pelo que ele com seu olhar transfigura que podemos, interrogativamente, incertamente, inquietamente, conhecer-lhe a vida." (SENA, 1988, p. 157) Se pensarmos que o dançarino, "pelo rosto e pelos seus gestos", ordena o tempo, engendra a duração; e que a fotografia é por excelência trabalho do olhar que transfigura o real, teremos nesta imagem de um dançarino fotografado uma espécie de fórmula para a matéria já transformada do mundo que se oferece agora ao conhecimento e à reflexão.

Continua Sena: "E, se não fora a poesia olhando a história, nenhuma vida em verdade conheceríamos, nem a nossa própria." (SENA, 1988, p. 157). Este o trabalho da metamorfose como proposto pelo poeta num livro que se pretende "epítome da história humana através da arte" (SENA, 1988, p. 159): operação de transfiguração e conhecimento, que busca dar a ver a história do homem - ou o homem em sua história apreendendo-a em momentos decisivos, críticos, instantes significativos de concentração de tempo e sentidos. Trabalho que poderíamos dizer fotográfico, que tomaria a fotografia como seu modelo teórico ou como sua experiência fundamental.

Parece desmentir-se, assim, aquela impressão de que as fotografias que acompanham os poemas de Metamorfoses constituem simples reproduções, talvez dispensáveis, das obras com as quais Sena dialoga. Mais do que meras ilustrações destes objetos, elas aludiriam à prática do poeta, ilustrando, portanto, a ação mesma dos poemas: meditar sobre imagens em que se pode ler - transfigurada e complexamente concentrada - a história humana, numa busca de conhecimento cujo 


\section{fundamento ético é utopia de redenção.}

Já Walter Benjamin percebera a vocação da imagem fotográfica técnica e mágica - para aninhar o futuro naquilo já há muito extinto (BENJAMIN, 1994, p. 94). Criando instantes sempre presentes, impregnados de pulsões históricas, a fotografia seria o fenômeno exemplar que poderia "fazer explodir o continuum da história", convertendo o "tempo homogêneo e vazio" num "tempo saturado de agoras" (BENJAMIN, 1994, p. 229-30) Temporalidade esta criada por Sena em Metamorfoses, "epítome da história", síntese de seus momentos decisivos segundo a arte, recolhidos em fotografias e poemas que são, também eles, ao modo fotográfico, lugares de confluência de tempos passado e futuro num presente adensado - e apelos à redenção. Assim, para lembrarmos apenas alguns, a gazela ibérica que "suspensa nas três patas se repousa" (SENA, 1988, p. 59), "as gerações que, inscientes, / viveram e morreram, dia a dia, até /àquela morte que encenando vinham" na "Pietà de Avignon" (SENA, 1988, p. 83-4), a cadeira testemunho da vida e do destino de Van Gogh (SENA, 1988, p. 115-6), os sábios impropérios de Camões (SENA, 1988, p. 95) e, claramente, o benjaminiano chamado messiânico às gerações futuras da "Carta a meus filhos sobre os fuzilamentos de Goya" (SENA, 1988, p. 123-4). Relendo a história a partir destes momentos significativos do passado, suspensos como em fotografias e que se fazem reconhecer pelo presente, Sena a reconstrói em Metamorfoses.

Inserido neste curso de uma historicidade repensada mais de dez anos depois de sua primeira publicação e dialogando de fato com uma fotografia, objeto que teria sido, como consideramos, o modelo teórico fundamental desta reescritura poética da história, "Dançarino de Brunei" se revela, então, mais do que uma nova metamorfose - "meditação aplicada" a uma obra, como diria Sena (1988, p. 158) - meditação aplicada ao próprio trabalho da metamorfose. Segundo a temporalidade dialética de Benjamin, seria este poema, no futuro dos demais, a sua origem, o lugar de sua recognoscibilidade, da revelação de seu sentido, de seu trabalho. Ou seja: exercício de suspensão do tempo num momento decisivo, impregnado de significação, que dá a ver a criação essencial do homem: a consciência de sua própria humanidade - "humana perfeição /que gente gera num saber da vida." - e faz ouvir o apelo último pela redenção, pela utopia. Ainda que isto implique, segundo o olhar crítico do poeta, o sacrifício da civilização tal como se desenvolveu: "Quando será que de ocidente a morte/ virá matar-nos, antes que matemos/com deuses feitos homens os humanos deuses/ que já tão poucos sobrevivem límpidos/ como este corpo se dançando em si/ (e as mãos paradas segurando os ares)?".

Neste meio em suspensão projetado pela imagem e pelo poema, a utopia permanece: humanas mãos sustentam os ares e o dançarino de Brunei, trançando as linhas abstratas e geométricas do espaço pobre e gradeado de sua prisão, aponta a abertura, conduz à passagem para um espaço indefinível na claridade excessiva da fotografia, território ainda por conquistar. 


\section{REFERÊNCIAS BIBLIOGRÁFICAS}

BENJAMIN, Walter. Pequena história da fotografia. In: _. Magia e técnica, arte e política. Trad. Sérgio Paulo Rouanet. São Paulo: Brasiliense, 1994. p. 91-107.

Sobre o conceito da história. In: - Magia e técnica, arte e política. Trad. Sérgio Paulo Rouanet. São Paulo: Brasiliense, 1994. p. 222-232.

KRAUSS, Rosalind. O fotográfico. Trad. Anne Marie Davée. Barcelona: Gustavo Gilli, 2002.

MALLARMÉ, Stéphane. Ballets. In: Igitur, divagations, Un coup de dés. Paris: Gallimard, 2003.

MERLEAU-PONTY, Maurice. O olho e o espírito. Trad. Paulo Neves e Maria Ermantina Pereira. São Paulo: Cosac e Naify, 2004.

SENA, Jorge de. Poesia II. Lisboa: Edições 70, 1988.

VALÉRY, Paul. La philosophie de la danse. Ir. _. Oeuvre 1. Variété.Théorie politique et esthétique. Paris: Gallimard, 1957. p. 1390-1403.

. A alma e a dança e outros diálogos. Trad. Marcelo Coelho. Rio de Janeiro: Imago, 1996. 